Thorax (1973), 28, 448.

\title{
Transposition of the great arteries
}

\section{A review of 37 cases after Mustard's operation}

\author{
H. N. C. I HENACHO, R. G. PATEL, S. P. SINGH, \\ R. ASTLEY, and C. G. PARSONS
}

The Children's Hospital, Birmingham B16 8ET

\begin{abstract}
Ihenacho, H. N. C., Patel, R. G., Singh, S. P., Astley, R., and Parsons, C. G. (1973). Thorax, 28, 448-452. Transposition of the great arteries. A review of 37 cases after Mustard's operation. Thirty-seven children with transposition of the great arteries have undergone Mustard's operation in Birmingham Children's Hospital from May 1968 to December 1971. Thirtythree of these had simple transposition of the great arteries and four were complicated. All but two had had some previous palliative procedures. Ten patients died before discharge from hospital and there were two late deaths, one after three months and the other after eight months. Bleeding, dysrhythmia, and hypotension were common immediate postoperative complications, while recurrent heart failure and persistent atrioventricular block occurred in five and four patients respectively.
\end{abstract}

Mustard's operation (Mustard, 1964; Mustard et al,. 1964) is now a standard procedure for the treatment of transposition of the great arteries (TGA). It is a satisfactory operation for uncomplicated cases such as transposition with atrial septal defect (Breckenridge et al., 1972), offering hope for a condition which otherwise has an appalling prognosis (Leibmann, Cullum, and Bellock, 1969). Parsons, Astley, Burrows, and Singh (1971) reported the result obtained in the first 65 infants who had been treated by balloon atrial septostomy at the Children's Hospital, Birmingham, and we now report our experience with the first 37 children who have undergone Mustard's operation.

\section{CLINICAL MATERIAL}

Between May 1968 and December 1971, 37 children with TGA have undergone Mustard's operation. Twenty were males and 15 females. There were 32 cases of simple transposition and five were complicated. Two had an additional ventricular septal defect and one each, pulmonary stenosis, patent ductus arteriosus, and total anomalous pulmonary venous drainage. Teflon cloth was used for constructing the baffle in the first case, Dacron was used in the last six cases, while pericardium was used in the others. All operations were performed with cardiopulmonary bypass and moderate hypothermia.

AGE AND WEIGHT AT OPERATION The youngest patient was 6 months old and the oldest 69 months. Average age at operation was 34.45 months. Weight at operation ranged from $5.04 \mathrm{~kg}$ to $18.15 \mathrm{~kg}$ with a mean of 11.42 . The average age at operation has been $\mathbb{D}$ reduced over the four-year period (Table I).

T A B LE I

MUSTARD'S OPERATION 1968-71

\begin{tabular}{|c|c|c|c|c|c|}
\hline Year & $\begin{array}{c}\text { No. } \\
\text { Operated }\end{array}$ & $\begin{array}{c}\text { Average } \\
\text { Age at Op. } \\
\text { (mth) }\end{array}$ & $\begin{array}{c}\text { Average } \\
\text { Weight at } \\
\text { Op. (kg) }\end{array}$ & $\begin{array}{c}\text { Hospital } \\
\text { Deaths }\end{array}$ & $\begin{array}{c}\text { Late } \\
\text { Deaths }\end{array}$ \\
\hline \multirow[t]{2}{*}{$\begin{array}{l}1968 \\
1969 \\
1970 \\
1971\end{array}$} & $\begin{array}{r}33 \\
6 \\
12 \\
16\end{array}$ & $\begin{array}{l}42 \cdot 3 \\
43 \cdot 67 \\
25 \cdot 3 \\
26.6\end{array}$ & $\begin{array}{r}12.47 \\
12 \cdot 37 \\
11 \cdot 32 \\
9.53\end{array}$ & $\begin{array}{l}1 \\
3 \\
0 \\
6\end{array}$ & $\begin{array}{l}0 \\
0 \\
1: \\
1^{2}\end{array}$ \\
\hline & 37 & $34 \cdot 46$ & $11 \cdot 42$ & 10 & 2 \\
\hline
\end{tabular}

PREVIOUS PALliative PROCEDURES

Twenty-nine patients had balloon atrial septostomy (Rashkind and $\Omega$ Miller, 1966) while three had operative atrial $N$ septostomy. Four had atrial septectomy (Blalock and $\mathrm{N}$ Hanlon, 1950). Two infants did not have any palliative $\omega$ procedure; one had a satisfactory shunt through an $\underset{\gamma}{\sigma}$ atrial septal defect and the other had total anomalous 0 venous drainage into the right atrium.

ADDITIONAL OPERATIONS Five patients had some other $T$ operation at the time of the Mustard procedure $\bar{O}$ (Table II). One ligation of patent ductus arteriosus, one pulmonary valvotomy, and one correction of $\frac{\Omega}{\mathbb{Q}}$ supracardiac total anomalous venous drainage were 2 performed. Two patients had a repair of the ventricular septal defect through the tricuspid valve. Four 
T A B L E I I

ADDITIONAL OPERATIONS DURING CORRECTION OF TRANSPOSITION OF THE GREAT ARTERIES

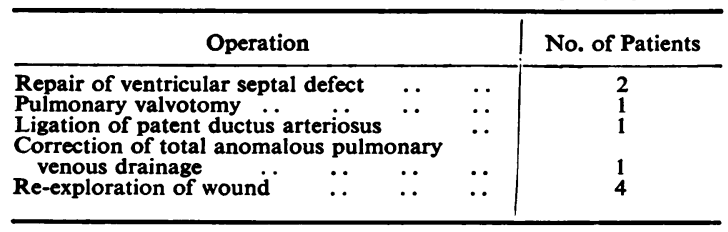

T A B L E I II

DURATION OF STAY IN HOSPITAL FOLLOWING MUSTARD'S OPERATION

\begin{tabular}{c|c|c}
\hline Year & $\begin{array}{c}\text { No. of Patients } \\
\text { Surviving Mustard's } \\
\text { Operation }\end{array}$ & $\begin{array}{c}\text { Average } \\
\text { Duration of Stay } \\
\text { (days) }\end{array}$ \\
\hline 1968 & 2 & 37 \\
1969 & 3 & $27 \cdot 7$ \\
1970 & 12 & $23 \cdot 4$ \\
1971 & 10 & $17 \cdot 4$ \\
\hline & 27 & $26 \cdot 2$ \\
\hline
\end{tabular}

had the chest re-explored for evacuation of blood clot within 24 hours of the Mustard's operation.

TOTAL DURATION OF POSTOPERATIVE STAY IN HOSPITAL One patient was fit to be discharged after six days. The majority of patients were discharged within four weeks. With increasing experience of the operation and improving postoperative care, there has been a reduction in the duration of hospital stay (Table III).

DEATHS There were 10 deaths in the immediate postoperative period. Seven of these had uncomplicated TGA, two were complicated by a ventricular septal defect, and one by total anomalous pulmonary venous drainage. Prolonged hypotension was the cause of seven deaths, four within 24 hours, two on the fourth, and one on the fifth day. One patient who died on the tenth day had evidence of severe cerebral damage demonstrated by electroencephalography. Pyopneumothorax and septicaemia caused one death on the fifteenth day while another death occurred after a stormy postoperative period of 34 days during which the patient had disturbances of rhythm - nodal rhythm and frequent ventricular ectopics, not responding to treatment.

Two late deaths occurred after satisfactory recovery from operation. One suffered transient loss of consciousness (less than a minute's duration) three months after operation, but no cause was found. Following an attack of vague abdominal pain he died suddenly. Necropsy failed to establish the cause of death. Another patient died eight months after operation, soon after com- pletion of the cardiac catheterization which was performed as part of the investigation of recurrent cardiac failure.

POSTOPERATIVE COMPLICATIONS The following complications were recorded.

Bleeding Wound bleeding occurred commonly but in the majority of patients was slight and stopped within 24 hours. In all four cases where bleeding was excessive the chest was re-opened for evacuation of clot. One of these patients died.

Disturbance of rhythm Transient disturbances of rhythm, most commonly nodal rhythm and supraventricular tachycardia, were observed during the first few days in about one-third of our patients. Treatment was not usually required. One had alternating episodes of nodal tachycardia and atrial fibrillation soon after operation, reverting to sinus rhythm on the sixth day. In one case bradycardia was noted, especially when the patient was lying on the left side. This ceased after two days but he developed A-V nodal rhythm after the fifth day. When last seen four months later he was well and in sinus rhythm. Nodal rhythm and frequent ventricular ectopics preceded death on the thirty-fourth day in one patient while another whose A-V nodal rhythm persisted over the first week was eventually discharged well but in $2: 1$ block.

However. dysrhythmias in two children have been troublesome. In a boy aged 8 (case 5 , Table IV) episodes of paroxysmal supraventricular tachycardia, atrial flutter, and fibrillation with a ventricular rate of 220 to 300 per minute necessitated three readmissions. Initially, these responded to intravenous administration of lignocaine and digoxin. The last episode which occurred nine months after operation was resistant to lignocaine but was terminated by intravenous propranolol. He has been maintained on oral propranolol, and the episodes of paroxysmal atrial tachycardia now occur infrequently, usually after a respiratory infection, and are of shorter duration. A 3-year-old girl (case 11, Table IV) was re-admitted with atrial tachycardia and heart failure four months after Mustard's operation. She had been having a maintenance dose of digoxin $(0.05 \mathrm{mg}$ twice daily orally) since operation. Sinus rhythm was restored with intravenous propranolol followed by a direct current countershock of 25 joules. Digoxin and diuretics were continued and when last seen she was well, in nodal rhythm with a ventricular rate of about 60 but no evidence of heart failure. 
Complete atrioventricular block occurred in six patients soon after operation (Table IV). Temporary transvenous pacing was used in two of these immediately the condition was recognized, and was continued until spontaneous reversion to sinus rhythm after 48 hours. One child aged 8 years (case 3, Table IV) has required permanent pacemaking with an inductive coupled pacemaker (Abrams, Hudson, and Lightwood, 1960). Ventricular rate has remained satisfactory in three other children with atrioventricular block.

T A B L E I V

DYSRHYTHMIAS AFTER MUSTARD'S OPERATION

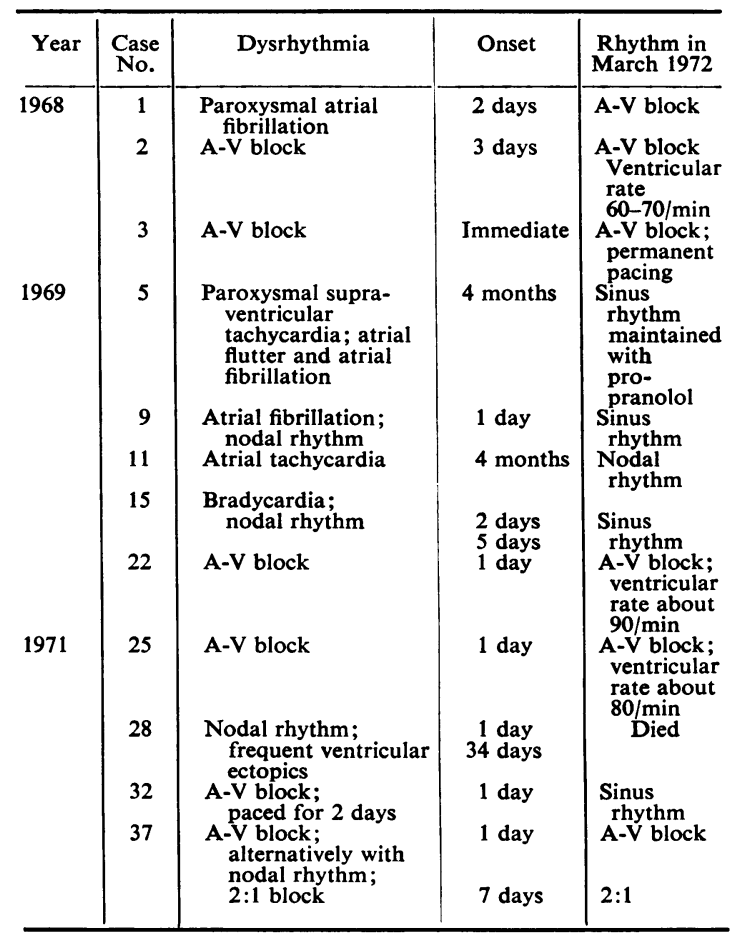

Recurrent cardiac failure Five patients have had recurrent cardiac failure which was sufficiently severe to require inpatient treatment on three occasions. All five have been taking digoxin and large doses of diuretics since operation. Two have been shown to have obstruction of the systemic venous return due to contraction in the intra-atrial baffle. Details of these cases will be reported in another communication.

\section{DISCUSSION}

Mustard (1968), in a review of further experience with his operation for transposition of the great arteries with an intact ventricular septum, recommended a minimum weight for operation of $9.0 \mathrm{~kg}$. Over the years we have tended in this centre to operate on younger children and the average $\frac{\bar{\omega}}{\sigma}$ weight has dropped from $12.5 \mathrm{~kg}$ in 1968 to $9.5 \mathrm{~kg} \nsubseteq$ in 1971. Children with an additional ventricular septal defect required early operation to prevent pulmonary vascular disease developing; it is often? an early complication (Viles, Ongley, and Titus, $\vec{\omega}$ 1969; Ferencz, 1966). In patients with an intacto ventricular septum early operation is designed to $\vec{x}$ avert the risk of intravascular thrombosis to whichi these children are exposed between the time of septostomy and corrective surgery (Parsons et al., $\dot{+}$ 1971). Nine of our children weighed less than $9 \mathrm{~kg} \stackrel{\vec{\circ}}{ }$ and five died; of six children under 12 months을 three died (Table V). The problem of operatingon small babies is that of using extracorporealc

\begin{tabular}{|c|c|c|}
\hline $\begin{array}{c}\text { Age at Operation } \\
(\mathrm{mth})\end{array}$ & No. of Patients & Hospital Deaths \\
\hline \multirow[t]{2}{*}{$\begin{array}{r}0-12 \\
13-24 \\
25-36 \\
37-48 \\
49-60 \\
61+\end{array}$} & $\begin{array}{r}6 \\
12 \\
6 \\
7 \\
3 \\
3\end{array}$ & $\begin{array}{l}3 \\
2 \\
2 \\
0 \\
2 \\
1\end{array}$ \\
\hline & 37 & 10 \\
\hline
\end{tabular}

circulation. Dillard and others (1969) have oper-0 ated on children less than 6 months old using deepê hypothermia and surface cooling which allowedo total circulatory arrest for periods of up to 60. minutes without extracorporeal circulation. Seven infants were described, their ages ranging from 3 days to 11 months and their weights 3.0 to $6.9 \mathrm{~kg}$. Four survivors have been followed up for between 12 and 30 months. Of the three who died, twos. had severe pulmonary hypertension, and the third a hypoplastic left ventricle. Breckenridge et al. (1972) reported a successful operation using cardiopulmonary bypass in an infant 7 weeks old w $(4.5 \mathrm{~kg})$ and showed that the results of electives operation in infants under 12 months of age compared favourably with those of their whole series

Operation may be needed before the child? reaches the optimal weight, especially as delayo may not result in significant additional growth of these children (Waldhausen et al., 1970).

The mortality of Mustard's operation in ourp hands has not been as low as was originallyo expected (Parsons et al., 1971). There were 10 hospital deaths, a mortality of $27 \%$; of theseg 
seven $(18.9 \%)$ had uncomplicated TGA. Mustard (1964) reported five survivors out of seven. In a review of a series of 65 patients operated upon at the Mayo Clinic between 1964 and 1967 there were 25 hospital deaths, 35\% (Danielson et al., 1971). The majority of these cases were complicated and there were only three deaths out of 25 uncomplicated cases. Aberdeen (1971) reported 10 deaths out of $78(13 \%)$ uncomplicated cases from the Hospital for Sick Children, London, and in a recent series of 200 from the same hospital there was an overall hospital mortality of $18 \%$ and of $11 \%$ in the uncomplicated cases (Breckenridge et al., 1972).

Some postoperative bleeding is not uncommon after operation in patients with cyanotic congenital heart disease (Ekert, Gilchrist, Stanton, and Hammond, 1970). Danielson and others (1971) reported six re-explorations for postoperative bleeding, which was a relatively frequent problem in their series. The report of Clarke and BarrattBoyes (1967) emphasizes that the chest should be re-explored when the pulmonary oedema and hypotension are associated with wound bleeding.

Dysrhythmia in the immediate postoperative period is common, sometimes contributing to death but often transitory and of no consequence. Mustard (1964) mentioned transitory dysrhythmia, and in a further report stated that dysrhythmia disappeared four to six weeks after operation (Mustard, 1968). Six of the 12 patients reported by Waldhausen and others (1970) were in nodal rhythm at the end of the operation. Only one needed transient cardiac pacing and all left hospital in sinus rhythm. Zuberbuhler and Bauersfeld (1967) reported two cases of unusual dysrhythmia; one had a variable degree of sinoatrial block and the other had two levels of block in the atrioventricular node. These dysrhythmias were attributed to the suture line interfering with the sino-atrial or atrioventricular nodes. Both patients had excellent results from the operation even though the dysrhythmia persisted. By modification of the operative technique, including placing sutures away from the atrioventricular node and the bundle of His, Breckenridge et al. (1972) demonstrated a significant reduction in the incidence of atrial flutter and atrioventricular dissociation, a significant cause of morbidity and mortality in their series. Complete atrioventricular dissociation occurred in five cases reported by Danielson et al. (1971), all of whom had repair of an additional ventricular septal defect. They all died. One of our six cases of atrioventricular block had a ventricular septal defect while the others had uncomplicated transposition of the great arteries.

Parsons et al. (1971) reported 32 deaths out of 65 infants after palliative procedures and expressed the hope that earlier Mustard's operation might improve the prognosis. Our experience seems to support this.

We wish to thank Mr. L. D. Abrams and Mr. K. D. Roberts, who performed the operations, for their unfailing help.

H.N.C.I. is indebted to the United Birmingham Hospitals for financial support.

\section{REFERENCES}

Aberdeen, E. (1971). Correction of uncomplicated cases of transposition of the great arteries. British Heart Journal, 33, Suppl., p. 66.

Abrams, L. D., Hudson, W. A., and Lightwood, R. (1960). A surgical approach to the management of heart-block using an inductive coupled artificial cardiac pacemaker. Lancet, 1, 1372.

Blalock, A., and Hanlon, C. R. (1950). The surgical treatment of complete transposition of the aorta and the pulmonary artery. Surgery, Gynaecology and Obstetrics, 90, 1.

Breckenridge, I. M., Oelert, H., Stark, J., Graham, G. R., Bonham-Carter, R. E., and Waterston, D. J. (1972). Mustard's operation for transposition of the great arteries. Lancet, 1, 1140.

Clarke, C. P., and Barratt-Boyes, B. G. (1967). The cause and treatment of pulmonary edema after the Mustard operation for correction of complete transposition of the great vessels. Journal of Thoracic and Cardiovascular Surgery, 54, 9.

Danielson, G. K., Mair, D. D., Ongley, P. A., Wallace, R. B., and McGoon, D. C. (1971). Repair of transposition of the great arteries by transposition of venous return. Journal of Thoracic and Cardiovascular Surgery, 61, 96.

Dillard, D. H., Mohri, H., Merendino, K. A., Morgan, B. C., Baum, D., and Crawford, E. W. (1969). Total surgical correction of transposition of the great arteries in children less than six months of age. Surgery, Gynaececology and Obstetrics, 129, 1258.

Ekert, H., Gilchrist, G. S., Stanton, R., and Hammond, D. (1970). Hemostasis in cyanotic congenital heart disease. Journal of Paediatrics, 76, 221.

Ferencz, C. (1966). Transposition of the great vessels: pathophysiologic considerations based upon a study of the lungs. Circulation, 33, 232.

Leibmann, J., Cullum, L., and Bellock, N. B. (1969). Natural history of transposition of the great arteries. Anatomy and birth and death characteristics. Circulation, 40, 237.

Mustard, W. T. (1964). Successful two-stage correction of transposition of the great vessels. Surgery, 55, 469. (1968). Recent experiences with surgical management of transposition of the great arteries. Journal of Cardiovascular Surgery, 9, 532. 
Keith, J. D., Trusler, G. A., Fowler, R., and Kidd, L. (1964). The surgical management of transposition of the great vessels. Journal of Thoracic and Cardiovascular Surgery, 48, 953.

Parsons, C. G., Astley, R., Burrows, F. G. O., and Singh, S. P. (1971). Transposition of great arteries. A study of 65 infants followed for 1 to 4 years after balloon septostomy. British Heart Journal, 33, 725.

Rashkind, W. J., and Miller, W. W. (1966). Creation of an atrial septal defect without thoracotomy. A palliative approach to complete transposition of the great arteries. Journal of the American Medical Association, 196, 991.
Viles, P. H., Ongley, P. A., and Titus, J. L. (1969). The spectrum of pulmonary vascular disease in transposition of the great arteries. Circulation, 40, 31.

Waldhausen, J. A., Pierce, W. S., Rashkind, W. J., Miller W. W., and Friedman, S. (1970). Total correction of transposition of the great arteries following balloon atrioseptostomy. Circulation, Suppl. II, pp. 41-42; II, p. 123.

Zuberbuhler, J. R., and Bauersfeld, S. R. (1967). Unusualc arrhythmias after corrective surgery for transposition of the great vessels. American Heart Journal, 73, 752. 